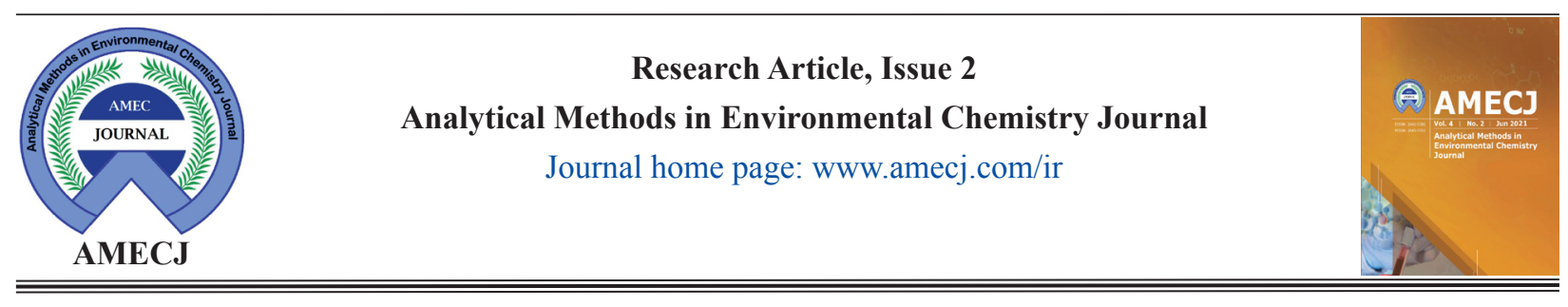

\title{
Evaluation and determination of occupational and environmental exposure of lead in workplace air and human workers based dispersive ionic liquid solid phase micro extraction in battery manufacturing factories from Iran
}

\author{
Somayeh Mirza ${ }^{a, *}$ and Azadeh Yahya Meymandi ${ }^{b}$ \\ a Ph.D in Environment Chemistry and Management, Department of Environmental Management, Faculty \\ of Natural resources and Environment, Science and Research branch, Islamic Azad University, Tehran, Iran. \\ ${ }^{\mathbf{b}}$ Faculty of Science, Department of chemistry, University of Birjand, Birjand, Iran
}

\section{A R T I C L E I N F O :}

Received 5 Mar 2021

Revised form 19 May 2021

Accepted 3 Jun 2021

Available online 29 Jun 2021

Keywords:

Lead,

Human whole blood,

Workplace air,

Nanotechnology,

Dispersive ionic liquid solid phase

micro extraction,

Battery manufacturing factories

\begin{abstract}
A B S T R A C T
The exposure of lead in workplace air and human workers of battery manufacturing factory was evaluated determined by nanotechnology since 2019-2020. Human whole blood (HWB) for subject and healthy peoples $(25-55$, Men, $40 \mathrm{~N})$ and workplace air $(40 \mathrm{~N})$ was prepared based on NIOSH sampling. $10 \mathrm{~mL}$ of HWB samples added to 20 $\mathrm{mg}$ of mixture ionic liquid/ ligand ([HMIM] $\left.\left[\mathrm{PF}_{6}\right] / \mathrm{APDC}\right)$ modified on graphene oxide nanostructures(GONs) at $\mathrm{pH}=6$. After sonication, the lead ions separated/extracted by dispersive ionic liquid solid phase micro extraction (DIL-SPME) and determined by flame atomic absorption spectrometry (F-AAS). All air samples in workplace were analyzed based on NIOSH process. The results showed us the negative correlation between $\mathrm{Pb}$ concentration in human blood subject and healthy peoples $(r=0.24)$. The range concentrations of lead in human subject, healthy peoples and workplace air were obtained 193.4543.7 $\mu \mathrm{g} \mathrm{L}{ }^{-1}, 85.6-175.9 \mu \mathrm{gL}^{-1}$ and 44.7-81.5 $\mu \mathrm{gm}^{-3}$, respectively. The LOD, linear rang, enrichment factor(EF) and RSD\% were achieved $1.25 \mu \mathrm{g} \mathrm{L}^{-1}, 5.0-310 \mu \mathrm{g} \mathrm{L}^{-1}, 19.6$ and less than $5 \%$ by procedure. The method was validated by standard reference material (SRM), the electrothermal atomic absorption spectrometry (ET-AAS) and ICPMS analyzer for human samples.
\end{abstract}

\section{Introduction}

Heavy metals have toxic effects in environmental and human health which it causes main problem in many human organs such as brain. Lead $(\mathrm{Pb})$ with dangerous properties in human consider as a hazardous chemical [1]. The battery and chemical factories use the lead in their products. The lead enters in environment by various sources such as, water, soil, the medical

\footnotetext{
*Corresponding Author: Somayeh Mirza

Email: somayeh.mirza@gmail.com

https://doi.org/10.24200/amecj.v4.i02.143
}

industries, air dust, water and gas pipes, paint factories and chemical products [2-5]. Lead causes many problem in human organs such as, the nervous central system (insomnia, delirium, cognitive deficits and tremor), kidney, liver, gastrointestinal and bone disorders [6,7]. Also, an acute poisoning of lead cause to neurological defect include, pain, muscle weakness and numbness. In biochemistry, the lead can be seen in various of proteins and amino acids. Also, lead bonded to sulfur groups of aminoacids such as cysteine (Cys) and a homoleptic and hemidirectic (SR)3 complex [8,9]. Moreover, 
lead can be complexed to copper/ zinc and caused brain problems. Therefore, the lead determination in the human biological samples (blood, serum and urine) with accurate and precise method must be considered. The environmental protection agency (EPA), NIOSH , OSHA, the National toxicology program (NTP) and food and drug administration (FDA) reported that the lead concentration in water, air and human blood samples are between 0.01-0.1 $\mathrm{mg} \mathrm{L}^{-1}$, less than $50 \mu \mathrm{g} \mathrm{m}^{-3}$ and $250 \mu \mathrm{g} \mathrm{L}^{-1}$, respectively [10-12]. Recently, many researchers reported the different lead analysis in water and human blood samples [13]. The various techniques such as flame atomic absorption spectrometry (F-AAS) [14,15], the electrothermal atomic absorption spectrometry (ET-AAS) [16], the inductively coupled plasma mass spectrometry(ICP-MS), the microwave plasma atomic emission spectrometry(MP-AES) [17, 18], the gas chromatography mass spectrometry GCMS [19] and laser-induced breakdown spectroscopy (LIBS)[20] were used for lead determination in different matrixes. Due to difficulty of matrixes and interferences, the extraction/preconcentration method for lead determination in blood samples is used. Various methodology such as, solid-phase extraction (SPE)[21], the magnetic-SPE [22], the dispersive liquid-liquid microextraction (DLLME) [23], the cloud point extraction (CPE) [24], the dispersive solid phase extraction (D-SPE), the ultrasound-assisted dispersive micro solid phase extraction (USA- $\mu$ SPE) [25], and the emulsification microextraction using a ionic liquid (IL-EME) [26] were reported. Recently, the dispersive ionic liquid solid phase micro extraction (DIL-SPME) for separation/ determination of heavy metals in liquid phases was used. The DIL-SPME method has many advantages such as high efficiency/recovery and easy to use in short time. The various sorbents include, the carbon nanotubes (CNTs) [27], the silica gel functionalized with thiosalicylic acid [28], and graphene/graphene oxide [29] was used for extraction/removal of heavy metals from solutions by scientists. The Ionic liquids were used for the separation of heavy metals from samples. Currently, safety, health and environmental assessments in factories can help manage pollutants in industry and pollutants are reduced in the long run after analysis [30].

In this study, the mixture of ionic liquid/ ligand ([HMIM] $\left.\left[\mathrm{PF}_{6}\right] / \mathrm{APDC}\right)$ modified on graphene oxide(NGO) was used for lead extraction from blood samples at $\mathrm{pH}=6$. The speciation of lead was achieved based on IL/APDC/NGO adsorbent before the DIL-SPME procedure. The method was validated in blood and water samples by spiking samples and ICP-MS analyzer.

\section{Experimental}

\subsection{Apparatus}

The GBC atomic absorption spectrophotometer equipped with flame and graphite tube ( electrical furnace) were used for the determination of lead in blood and serum samples (F-AAS, ET-AAS, GBC 932 plus, Australia). The Pal GF3000 as auto sampler accessory for ET-AAS was used as a low volume of samples for lead determination by injecting 1-100 $\mu \mathrm{L}$ of sample to graphite tube (wavelength $283.3 \mathrm{~nm}$, slit $0.5 \mathrm{~nm}$, lamp current $5.0 \mathrm{~mA}$ ). Also, the auto sampler accessory for flame technique was used $(0.5-5 \mathrm{~mL})$. After atomization process in flame or graphite tube, the ppm and ppb concentration of lead was determined in liquid samples, respectively (Table 1). The ICPMS analyzer with high sensitivity was used for as ultra-trace lead determination in human blood samples (Perkin Elmer, USA, $1100 \mathrm{~W}$; $14 \mathrm{~L} \mathrm{~min}^{-1}$; $1.2 \mathrm{sec}$ per mass; auxiliary gas $\left.1.1 \mathrm{~L} \mathrm{~min}^{-1}\right)$. The $\mathrm{pH}$ meter was used for measuring $\mathrm{pH}$ in blood samples (Metrohm, E-744, Switzerland). The shacking of samples was achieved by $300 \mathrm{rpm}$ speeds by vortex mixer (Thermo, USA) and samples centrifuged with Falcon accessory (4000 rpm, 5-30 mL of polypropylene conical tubes, USA). An ultrasonic bath was used for dispersing of solid phase in blood samples with the temperature controlling accessory between $10-100^{\circ} \mathrm{C}$ (HB120, USA). The X-ray diffraction (XRD) based on a Panalytical X'Pert PRO X-ray diffractometer was used. The scanning electron microscopy (SEM) images were obtained using a Tescan Mira, Field Emission Scanning Electron Microscope (FEG-SEM). 
Table 1. The AT-F-AAS and ET-AAS conditions for lead $(\mathrm{Pb})$ determination

\begin{tabular}{lll}
\hline Features & AT-F-AAS & ET-AAS \\
\hline Linear range & $0.1-6.2\left(\mathrm{mg} \mathrm{L}^{-1}\right)$ & $5-145\left(\mu \mathrm{g} \mathrm{L}^{-1)}\right.$ \\
Wavelength & $283.3 \mathrm{~nm}$ & $283.3 \mathrm{~nm}$ \\
Lamp current & $5.0 \mathrm{~mA}$ & $5.0 \mathrm{~mA}$ \\
Slit & $0.5 \mathrm{~nm}$ & $0.5 \mathrm{~nm}$ \\
Mode & Peak Area & Peak Area \\
Atomization & Air-Acetylene & Electrical \\
Auto Sampler & $0.5-5.0\left(\mathrm{~mL}^{-}\right)$ & $1-100(\mu \mathrm{L})$ \\
LOD & $0.03\left(\mathrm{mg} \mathrm{L}^{-1}\right)$ & $1.2(\mu \mathrm{g} \mathrm{L}-1)$ \\
$\mathrm{R}^{2}$ & 0.9998 & 0.9995 \\
\hline
\end{tabular}

\subsection{Reagents}

The standard solution of lead $\left(\mathrm{Pb}^{2+}\right)$ was purchased from Merck with a concentration of $1000 \mathrm{mg} \mathrm{L}^{-1}$ in $1 \% \mathrm{HNO}_{3}(\mathrm{CAS} \mathrm{N}: 119776,1 \mathrm{Li}$, Germany). The calibration standard of lead between 0.5 $60 \mu \mathrm{g} \mathrm{L}^{-1}$ was daily prepared by diluting of lead stock. Ammonium pyrrolidinedithiocarbamate as ligand (APDC, CAS N.: 169209-63-6) was prepared from Merck. Germany. Ultrapure water was purchased from Millipore Company (USA) for dilution of solutions or standards. The hydrophobic ionic liquid of 1-Hexyl-3-methylimidazolium hexafluorophosphate was prepared from Sigma Aldrich (CAS N: 304680-35). The $\mathrm{pH}$ of 6 was adjusted by sodium phosphate buffer solution (Merck, Germany, $\left(\mathrm{Na}_{2} \mathrm{HPO}_{4} / \mathrm{NaH}_{2} \mathrm{PO}_{4}\right)$. The polyoxyethylene octyl phenyl ether (TX-100), $\mathrm{HNO}_{3}, \mathrm{HCl}$, acetone, and butanol were purchased from Sigma Aldrich, Germany.

\subsection{Human and air sample}

For preparation of blood samples, the glass mixed in nitric acid $(1 \mathrm{M})$ for $24 \mathrm{~h}$ and washed with DW for 8 times. The low concentrations of lead in blood samples $\left(<250 \mu \mathrm{g} \mathrm{L}^{-1}\right)$, caused to the effect on accurate results. So, the process of blood sampling was carefully done based on standard methods. The $5 \mathrm{~mL}$ of blood samples were prepared from battery workers from Iran (40 Men, 25-55 age) due to world medical association declaration of Helsinki and dilution with DW up to $10 \mathrm{~mL}$. Clean tubes and syringes with plastic needles were purchased for Merck, Germany for blood sampling. The $10 \mu \mathrm{L}$ heparin (pure metals) was added to human blood sample. The blood samples were maintained frozen in refrigerator below $-4^{\circ} \mathrm{C}$.

The air sampling for lead was prepared based on Filter $(0.8 \mu \mathrm{m}$ cellulose ester membrane) by 7082 NIOSH method. The flowrate adjusted 1 to $4 \mathrm{~L} \mathrm{~min}^{-}$ ${ }^{1}$ and ashing process with $6 \mathrm{~mL}$ of $\mathrm{HNO}_{3}, 1 \mathrm{~mL}$ of $\mathrm{H}_{2} \mathrm{O}_{2}(30 \%)$ at $140{ }^{\circ} \mathrm{C}$ was achieved. The working standards covering the range $0.25-20 \mu \mathrm{g} \mathrm{mL}^{-1}$ of $\mathrm{Pb}$ used for calibration method (2.5-200 $\mu$ g lead per sample). The lead concentration in workplace air was determined by F-AAS and $\mathrm{D}_{2}$ or $\mathrm{H}_{2}$ continuum or Zeeman background correction used to control flame or molecular absorption. The working range between $0.05-1 \mathrm{mg} \mathrm{m}^{-3}$ for a $200 \mathrm{~L}$ of air sample was selected. In addition, the flow rate between 1.0 - $4.0 \mathrm{~L} \mathrm{~min}^{-1}$ for $8 \mathrm{~h}$ was used by personal pump.

\subsection{Synthesis of IL/GONPs}

The mixture ionic liquid with ligand ([HMIM] $\left[\mathrm{PF}_{6}\right] /$ APDC) modified on graphene oxide nanostructures(GONs) and used as adsorbent for lead extraction. The synthesis of graphene oxide (GO) was followed by the modified Hummers method [31-33]. First, $10 \mathrm{~g}$ of graphite powder was mixed with $500 \mathrm{~mL}$ of $\mathrm{H}_{2} \mathrm{SO}_{4}$ and stirred for one day. Then, $\mathrm{KMnO}_{4}(48 \mathrm{~g})$ was mixed to the above mixture at $55^{\circ} \mathrm{C}$. Next, the mixture was moved into

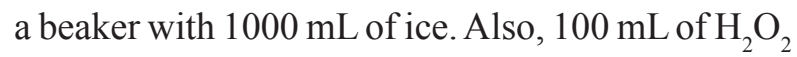
in $1000 \mathrm{~mL}$ of DW was added to the mixture up to create a yellow color. The product was washed with deionized water and $\mathrm{HCl}$ for many times and dried at $70{ }^{\circ} \mathrm{C}$. Then, $0.1 \mathrm{~g}$ of APDC mixed with $0.25 \mathrm{~g}$ 

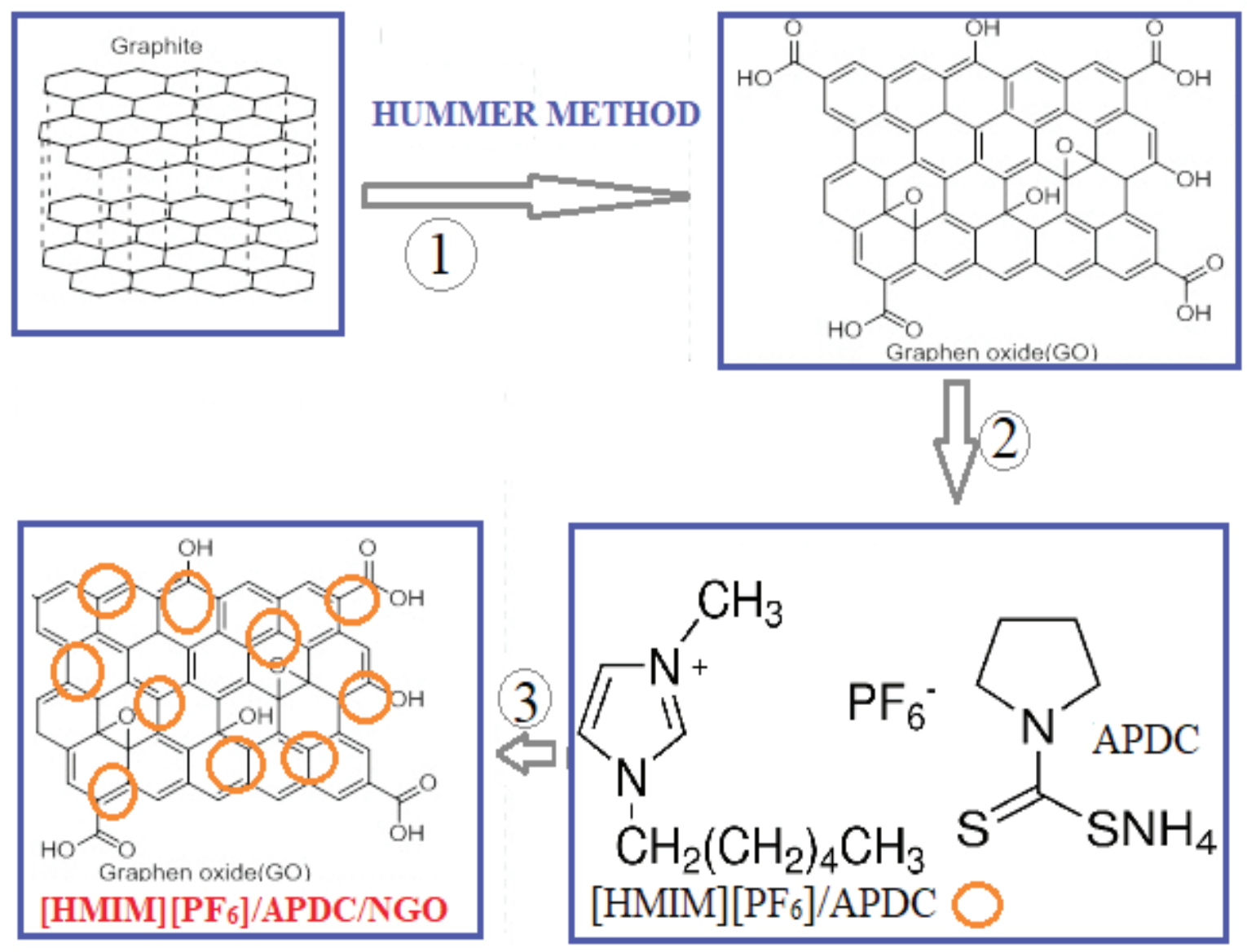

Fig.1. Synthesis of ([HMIM][ $\left.\left.\mathrm{PF}_{6}\right] / \mathrm{APDC}\right)$ modified on graphene oxide

of IL in presence of $2 \mathrm{~mL}$ of acetone and $0.2 \mathrm{~g}$ of GO. After increasing temperature up to $50^{\circ} \mathrm{C}$, the mixture of IL/APDC were uniformly modified on Go (Fig.1). Finally, $20 \mathrm{mg}$ of adsorbent selected for lead extraction in blood samples.

\subsection{Extraction Procedure}

In the DIL-SPME method, $10 \mathrm{~mL}$ of blood samples were used for extraction and determination of lead ions at $\mathrm{pH}$ 6.0. By procedure, $20 \mathrm{mg}$ of IL/APDC modified on GO were injected to human blood samples and standard solution $\left(5-310 \mu \mathrm{g} \mathrm{L}^{-1}\right)$ at $\mathrm{pH}=6.0$ (Fig.2). After sonication of samples for 3.0 $\mathrm{min}$, the lead separated and extracted with the APDC on adsorbent as sulfur coordination bonding in liquid phase $\left(\mathrm{Pb}^{2+} \rightarrow\right.$ : APDC/IL-GONPs). By centrifuging (5 min; $4000 \mathrm{rpm}$ ), the solid phase trapped in [HMIM] $\left[\mathrm{PF}_{6}\right]$ phase and collected from the samples in the end of the conical tube. The liquid phase was set aside and the lead ions back-extracted from ([HMIM] $\left[\mathrm{PF}_{6}\right] /$
APDC)/NGO adsorbent in $\mathrm{pH}=2\left(\mathrm{HNO}_{3}, 0.5 \mathrm{M}, 200\right.$ $\mu \mathrm{L}$ ) and diluted with $300 \mu \mathrm{L}$ of DW before determined by F-AAS. In addition, On the other hand, the $10 \mathrm{~mL}$ of standard solution was used based on the DIL-SPME procedure by the same conditions at $\mathrm{pH}=6.0$. A blank run without any lead ions was used for ten times. The calibration curve for lead in standards solutions was prepared. The analytical procedure was showed in Table 2. Validation was followed by CRM of lead and real samples, which was analyzed by ETAAS and ICP-MS analyzer. The concentration lead in work place air was achieved based on $7082 \mathrm{NIOSH}$ method for 40 workers and the mean concentration in

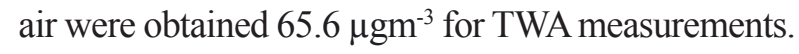
The recovery of lead procedure in blood samples based on APDC/IL-GONPs was obtained by the equation 1 . The $C_{i}$ is the primary concentrations and $C_{f}$ is the secondary concentration of $\mathrm{Pb}(\mathrm{II})$, which was determined by APDC/IL-GONPs coupled DILSPME procedure $(\mathrm{n}=8)$. 
$\mathbf{R} \%=\left(\mathbf{C}_{\mathbf{i}}-\mathbf{C}_{\mathbf{f}}\right) / \mathbf{C}_{\mathbf{i}} \times \mathbf{1 0 0} \quad(\mathbf{E q . 1}) \quad \mathrm{V}_{\mathrm{b}}$, respectively. Finally, the $\mathrm{C}\left(\mathrm{mg} \mathrm{m}^{-3}\right)$, of lead For workplace air, after determination lead in showed the concentration lead in air where the air filter, the concentrations $\left(\mathrm{C}_{\mathrm{s}}, \mu \mathrm{g} \mathrm{mL} \mathrm{m}^{-1}\right)$ of lead in volume sampled was $\mathrm{V}(\mathrm{L})$.

the sample air was achieved by NIOSH method (The average blank, $\mathrm{C}_{\mathrm{b}}$ ). The concentration in air calculated based on equation 2, the volumes $(\mathrm{mL})$ of the sample and media blanks is $\mathrm{V}_{\mathrm{s}}$ and

$$
C=\frac{C_{s} v_{s}-C_{b} v_{b}}{V}
$$

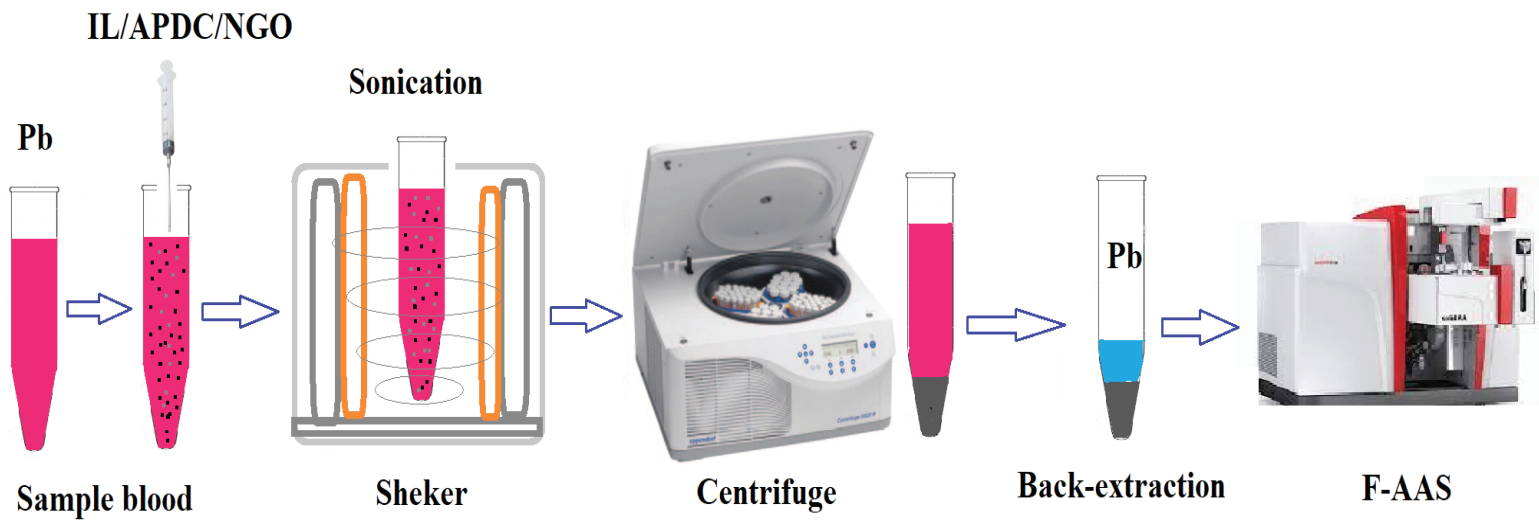

Fig.2. Lead extraction based on APDC/IL/NGO coupled to DIL-SPME procedure

Table 2. The analytical features for determination lead in human blood samples by DIL-SPME procedure

\begin{tabular}{lc}
\hline Features & value \\
\hline $\mathrm{pH}$ & 6.0 \\
Amount of APDC/IL modified on GONPs $(\mathrm{mg})$ & 20.0 \\
Sample volume of blood, serum $(\mathrm{mL})$ & 10.0 \\
Volume of sample injection & $0.5 \mathrm{~mL}$ \\
Linear range for blood & $5-310 \mu \mathrm{g} \mathrm{L}^{-1}$ \\
Mean RSD \%, n=8 & 4.6 \\
LOD for blood & $1.25 \mu \mathrm{g} \mathrm{L}^{-1}$ \\
Enrichment factor for blood & 19.6 \\
Volume and concentration of $\mathrm{HNO}_{3}$ & $0.2 \mathrm{~mL}, 0.5 \mathrm{M}$ \\
Shaking/Centrifuging time & $3.0 \mathrm{~min}, 5 \mathrm{~min}^{2}$ \\
Correlation coefficient & $\mathrm{R}^{2}=0.9995$ \\
\hline
\end{tabular}




\section{Results and discussion}

\subsection{Characterization}

XRD patterns of GO and APDC/IL/GO are similar and shown in Figure 3. Graphene oxide exhibits the sole main diffraction peak at $2 \theta=12^{\circ}$ corresponding to the oxygen functional groups which are intercalated between graphene sheets in the course of oxidation. The peaks at $2 \theta=12^{\circ}$ and $42.58^{\circ}$ are related to the diffraction planes of (002) and (100) respectively, which can be observed in the XRD patterns of both GO and APDC/IL/GO. However, existence of this peak at about $2 \theta=12^{\circ}$ agrees well with the modification of graphene oxide with APDC and IL.

The morphology of GO and APDC/IL/GO are evaluated by scanning electron microscope (SEM) (Fig. 4). According to the SEM images (Fig. 4I and 4II), Comparison between the SEM images of GO and APDC/IL/GO revealed that, the modification of GO had no prominent effect on the morphology of the graphene sheets.

\subsection{Optimization of proposed procedure}

The DIL-SPME procedure with new IL/APDC/ NGO was applied for the extraction and separation of lead ions in human blood samples. The high recovery for lead extraction was obtained by optimizing of parameters.

\subsubsection{The pH optimization}

The $\mathrm{pH}$ is the main factor for lead extraction in human blood samples by APDC ligand which was mixed with IL and modified on NGO. The various $\mathrm{pH}$ for lead extraction in blood samples was used and studied between 2-12. The results showed, the IL/APDC/NGO had highly lead extraction at $\mathrm{pH}$ of 5.5-6.5 $(<95 \%)$. The complexation of lead with APDC were decreased at $\mathrm{pH}$ less than 5 and

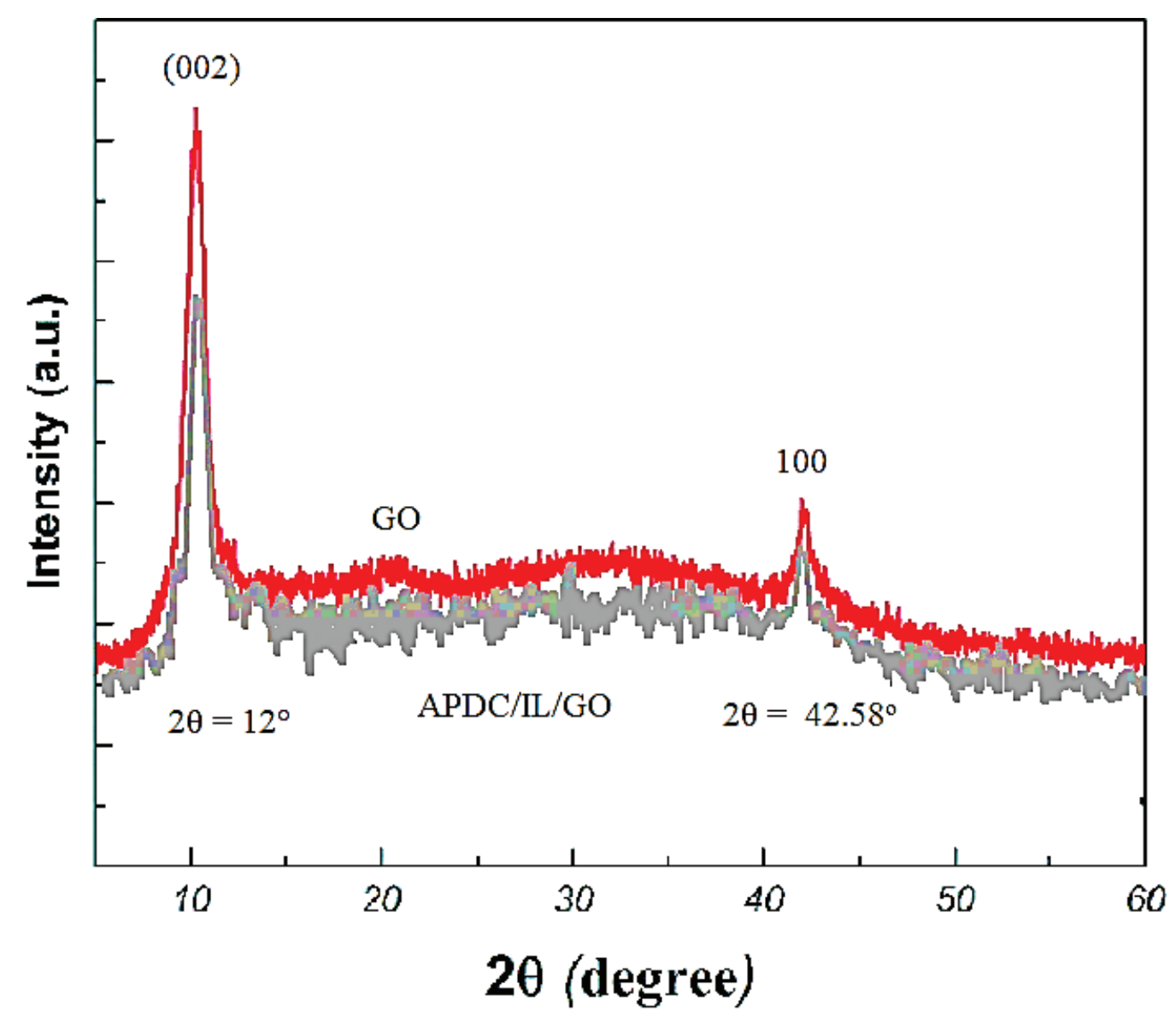

Fig.3. XRD of NGO and IL/APDC/NGO 

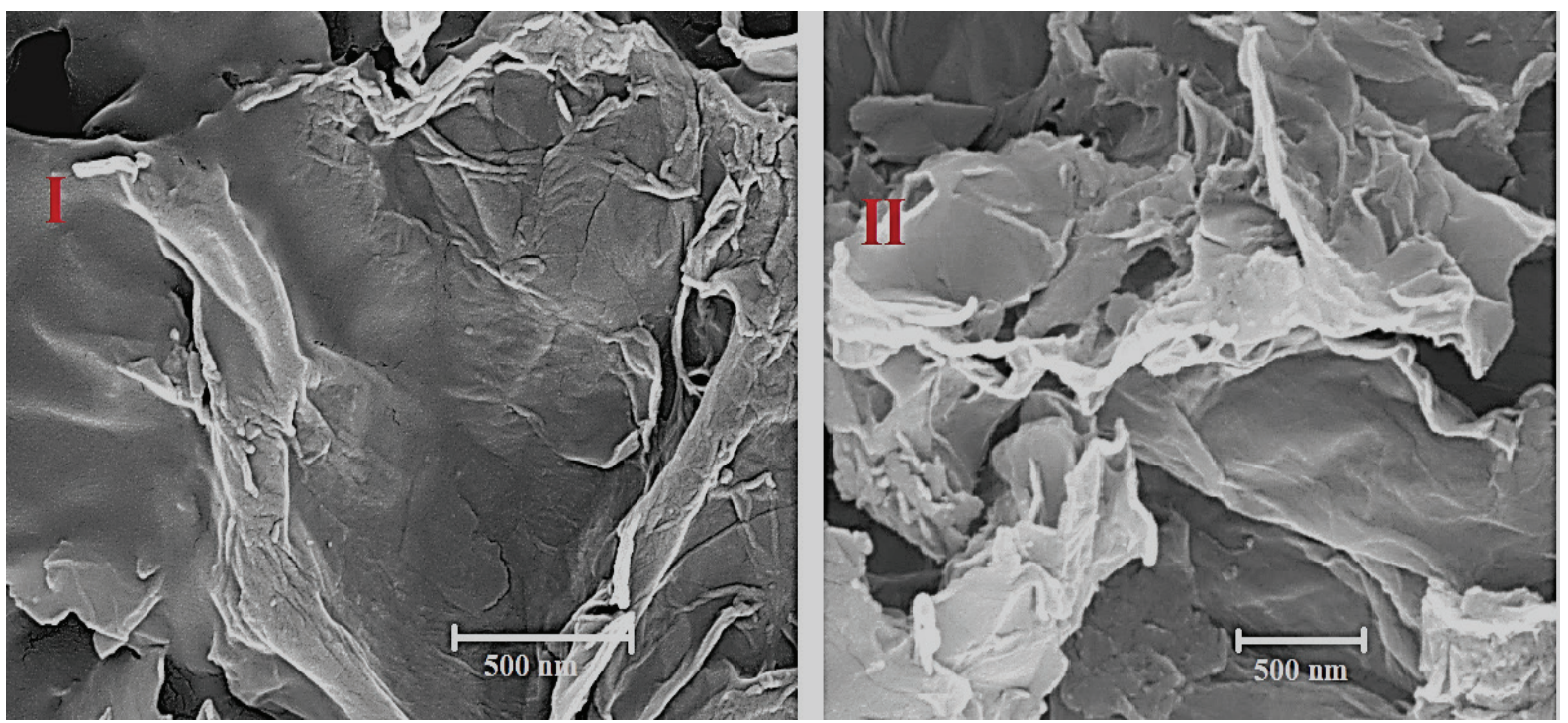

Fig.4. I (SEM of NGO II) SEM of IL/APDC/NGO

$\mathrm{pH}$ more than 6.5. So, the $\mathrm{pH}=6$ was selected as optimum $\mathrm{pH}$ for lead extraction in blood samples (Fig. 5). The mechanism of lead extraction depended on sulfur group in APDC which was created a dative bond with $\mathrm{Pb}$ ions in liquid phase $\left(\mathrm{Pb}^{2+} \rightarrow: \mathrm{S} \ldots\right.$...APDC/IL/NGO-GO). At lower $\mathrm{pH}$ the surface of adsorbent had positive-charge $(\mathrm{S}+)$ and extraction decreased due to similarity charges law. At $\mathrm{pH}$ of 6.0, the surface of APDC/ $\mathrm{IL} / \mathrm{NGO}$ have negatively charged $(\mathrm{S}-)$ and $\mathrm{Pb}(+)$ complexed by sulfur groups. Moreover, the lead participated in liquid phase $\left(\mathrm{Pb}(\mathrm{OH})_{2}\right)$ and the extraction efficiency was decreased at more than $\mathrm{pH}$ of 7 . Therefore, the $\mathrm{pH}=6$ used for further studies in blood samples.

\subsubsection{Optimization of APDC/IL/NGO mass}

The high extraction was achieved based on APDC/ IL/NGO mass which was depended to sulfur group of APDC as complexation. So, the mass of APDC/IL/NGO must be optimized conditions. The amounts of APDC/IL/NGO between 2-50 mg in human blood samples and standard solution were studied for lead extraction by DIL-SPME procedure. As Figure 6, the maximum recoveries were achieved for $\mathrm{Pb}$ extraction by $20 \mathrm{mg}$ of APDC/ $\mathrm{IL} / \mathrm{NGO}$ in human blood samples. So, $20 \mathrm{mg}$ of APDC/IL/NGO was selected for experimental run by DIL-SPME procedure. The extraction efficiency of lead had constant rate for more than $20 \mathrm{mg}$ of APDC/IL/NGO in blood samples.

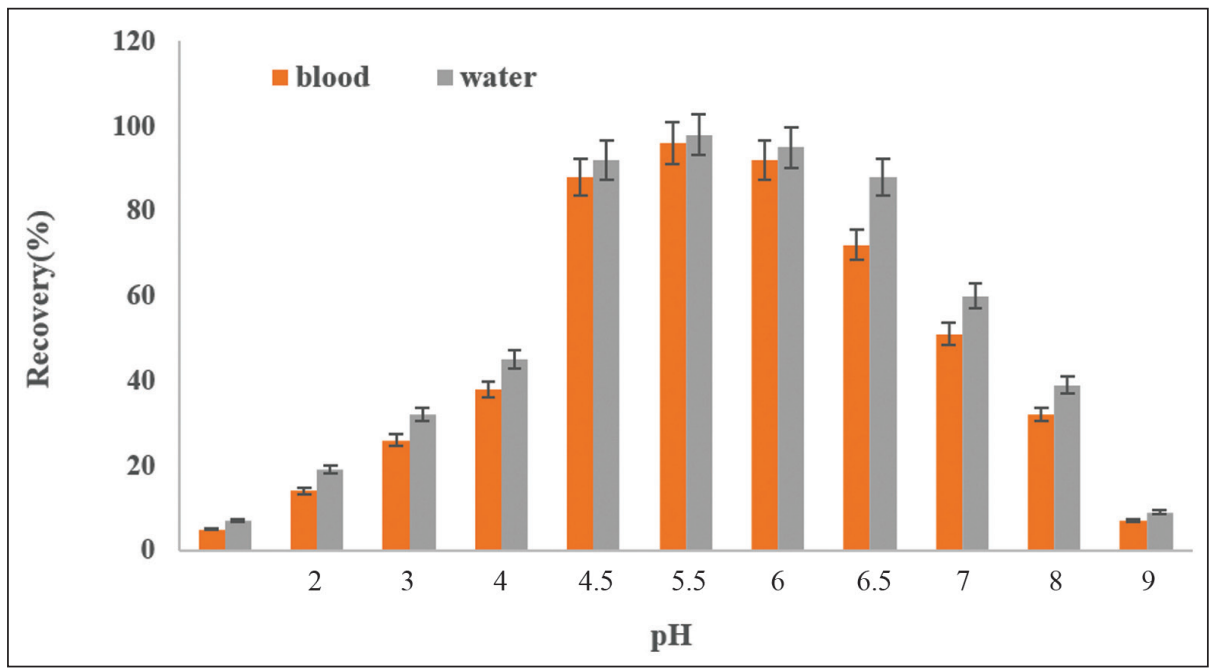

Fig.5. The effect of $\mathrm{pH}$ on lead extraction based on APDC/IL/NGO by DIL-SPME procedure 


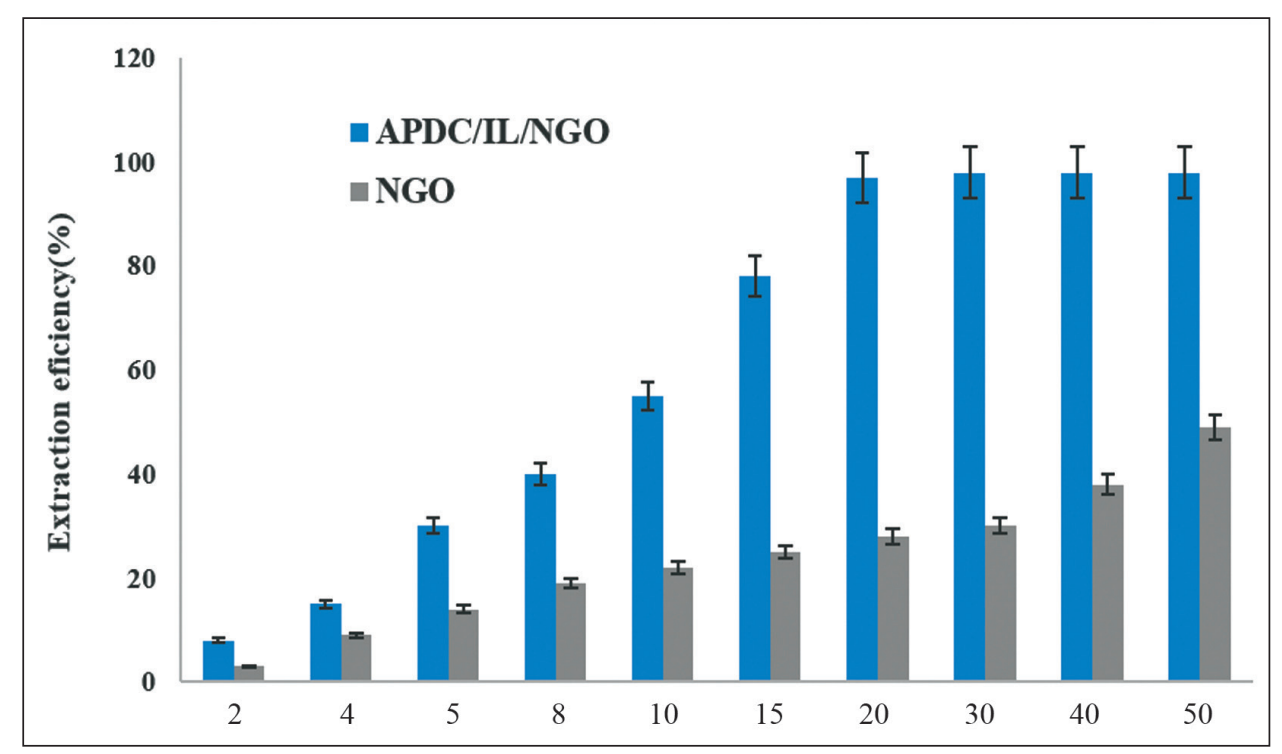

Fig.6. The effect of amount of APDC/IL/NGO on lead extraction based on APDC/IL/NGO by DIL-SPME procedure

\subsubsection{Optimization of sample volume and eluent} The volume and concentration of eluents such as acid or bases is important for back extraction $\mathrm{Pb}$ ions from APDC/IL/NGO were studied. The low/ high $\mathrm{pH}$ caused to dissociate the sulfur- $\mathrm{Pb}$ covalent bonds and released the $\mathrm{Pb}$ ions from adsorbent. So, the different reagents $\left(\mathrm{HCl}, \mathrm{HNO}_{3}\right.$, $\mathrm{CH}_{3} \mathrm{COOH}, \mathrm{H}_{2} \mathrm{SO}_{4}, \mathrm{H}_{2} \mathrm{CO}_{3}$ ) were used for the back-extraction of lead from APDC/IL/NGO to liquid solutions. The 0.1-1.0 molar of various eluents with different volumes from 0.1 to 0.7
$\mathrm{mL}$ was studied. Due to Figure 7, the efficient recovery obtained by $0.2 \mathrm{~mL}$ of $\mathrm{HNO}_{3}(0.5 \mathrm{M})$. In addition, the volume of blood and standard solutions for lead extraction based on APDC/IL/ NGO adsorbent was optimized from $1.0 \mathrm{~mL}$ to $20.0 \mathrm{~mL}$ for LLOQ and ULLOQ concentration of $\mathrm{Pb}$ (II) (5.0-310 $\left.\mu \mathrm{g} \mathrm{L}^{-1}\right)$. The results showed that the best recovery was achieved less than $10 \mathrm{~mL}$ for in blood samples at $\mathrm{pH}=6$. therefore, the 10 $\mathrm{mL}$ of blood or standard solution was used for further work (Fig. 8).

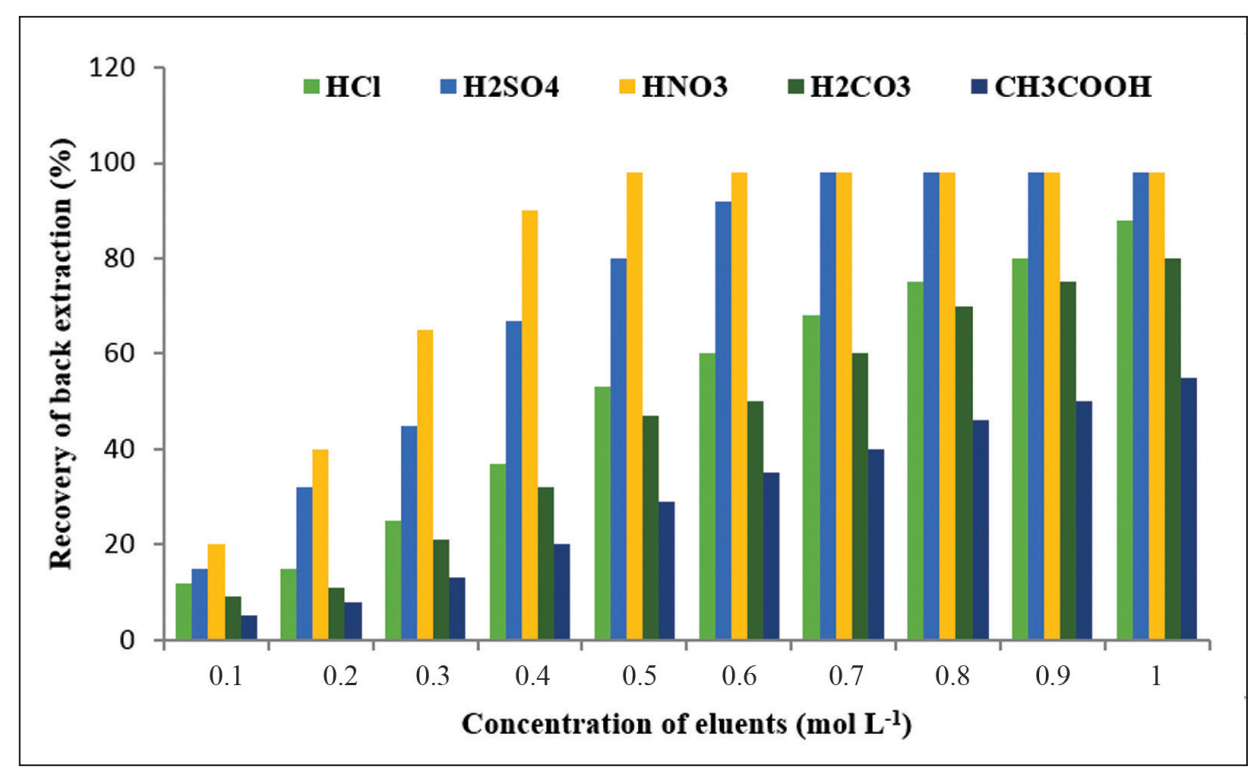

Fig.7. The effect of eluents on lead extraction based on APDC/IL/NGO by DIL-SPME procedure 


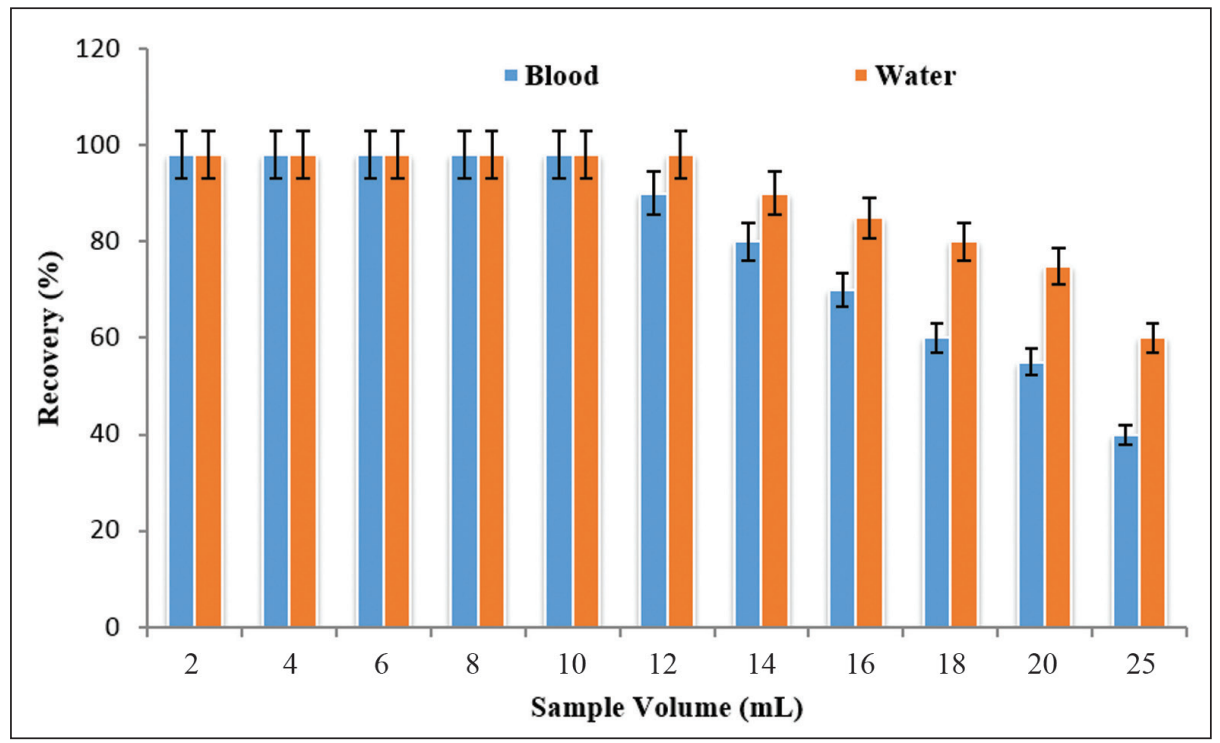

Fig.8. The effect of sample volume on lead extraction based on APDC/IL/NGO by DIL-SPME procedure

\subsubsection{Optimization of time, reusability and absorption capacity}

The time dispersion of APDC/IL/NGO adsorbent in blood or standard samples had a main factor for efficient extraction of lead. Moreover, the masstransference between APDC/IL/NGO and $\mathrm{Pb}$ ions was occurred at $\mathrm{pH}=6$ by DIL-SPME procedure. In optimized conditions, the sonication time was evaluated between $1-8 \mathrm{~min}$. the results showed that the sonication time of $3.0 \mathrm{~min}$ has maximum extraction of lead in blood samples. In addition, the centrifuging time between 1-10 $\min (4000 \mathrm{rpm})$ was used for collecting sorbent in end of conical tube. Based on results, $5 \mathrm{~min}$ of centrifuge time is enough time for efficient extraction of lead. Finally, the lead ions were back-extracted from APDC/IL/ NGO by changing $\mathrm{pH}$ and determined by F-AAS. The reusability of APDC/IL/NGO was obtained with many times extraction process by DIL-SPME procedure. The results showed, the DIL-SPME can be used for less than 7 cycles for lead extraction at optimized $\mathrm{pH}$ in room temperature. The absorption capacities for lead depended on chemical and physical properties of APDC/IL/NGO in bath system. The absorption capacities of APDC/IL/ NGO for $\mathrm{Pb}$ ions examined with $50 \mathrm{mg} \mathrm{L}^{-1}$ in optimized conditions. The adsorption capacity of $\mathrm{APDC} / \mathrm{IL} / \mathrm{NGO}$ and NGO for $\mathrm{Pb}$ ions was achieved $154.7 \mathrm{mg} \mathrm{g}^{-1}$ and $28.9 \mathrm{mg} \mathrm{g}^{-1}$, respectively.

\subsubsection{Interference cations and anions}

For extraction lead in blood samples, the effect of interference of ions was studied by DIL-SPME procedure. So, the concentrations of cations and anions in human blood such as $\mathrm{Cu}, \mathrm{Zn}, \mathrm{Mn}, \mathrm{Mg}, \mathrm{Ca}$, $\mathrm{Fe}$ and etc. (1-2 ppm) added to $10 \mathrm{~mL}$ of standard solution or human blood samples in presence of $300 \mu \mathrm{g} \mathrm{L}^{-1}$ of lead at $\mathrm{pH}=6$. The recovery of lead extraction in presence of the concomitant cations/ anions couldn't decreased at $\mathrm{pH}=6$. Therefore, the $\mathrm{Pb}$ ions can be extracted based on APDC/IL/NGO in blood samples in presence of some coexisting ions (Table 3).

\subsubsection{Real sample analysis}

The concentration of lead in human blood and standard samples was determined by DIL-SPME procedure. The lead was efficiently extracted based on APDC/IL/NGO adsorbent from human blood samples and obtained results were validated by electrothermal atomic absorption spectrometry (ET-AAS) and ICP-MS techniques (Table 4). In this study, the validation based on spiking real 
Table 3. The effect of interference cations and anions for lead extraction by the DIL-SPME procedure

\begin{tabular}{lcc}
\hline & $\begin{array}{c}\text { Mean ratio } \\
\text { Interfering Ions in blood (A) }\end{array}$ & Recovery (\%) \\
\cline { 2 - 3 } & $\left.\mathbf{P b} / \mathbf{C}_{\mathbf{P b}(\mathrm{III})}\right)$ & $\mathbf{P b}(\mathbf{I I})$ \\
\hline $\mathrm{Co}^{2+}, \mathrm{Fe}^{2+}$ & 550 & 99.3 \\
$\mathrm{Zn}^{2+}, \mathrm{Cu}^{2+}$ & 850 & 98.1 \\
$\mathrm{Mn}^{2+}, \mathrm{Mo}^{2+}$ & 600 & 96.5 \\
$\mathrm{I}^{-}, \mathrm{Br}^{-}, \mathrm{F}^{-}, \mathrm{Cl}^{-}$ & 1100 & 97.4 \\
$\mathrm{Na}^{+}, \mathrm{K}^{+}$ & 1000 & 99.3 \\
$\mathrm{Ca}^{2+}, \mathrm{Mg}^{2+}$ & 1200 & 98.4 \\
$\mathrm{CO}_{3}^{2-}, \mathrm{PO}_{4}^{3-}, \mathrm{NO}_{3}^{-}$ & 650 & 97.4 \\
$\mathrm{Ni}^{2+}$ & 300 & 98.1 \\
$\mathrm{Al}^{3+}, \mathrm{V}^{3+}, \mathrm{Cr}^{3+}$ & 900 & 97.7 \\
$\mathrm{Hg}^{2+}, \mathrm{Ag}^{+}$ & 120 & 98.2 \\
\hline
\end{tabular}

samples with a standard solution were achieved in human blood and serum samples by APDC/IL/ NGO adsorbent (Table 5). The results demonstrated the efficient recovery for lead ions in difficulty matrixes in blood samples. The spiked samples showed a accurate results for separation/extraction/ determination /preconcentration of human blood samples by APDC/IL/NGO adsorbent. As intra-day and inter-day analysis, the 40 human blood workers of battery manufacturing factories determined by same procedure ((25-55, Men, Iran) and compared to office people as control markers (Table 6).

Table 4. The validation of proposed method for lead extraction in human matrixes by ICP-MS and ET-AAS $\left(\mu \mathrm{gL}^{-1}\right)$

\begin{tabular}{|c|c|c|c|}
\hline Samples & ICP-MS * & DIL-SPME /F-AAS * & ET-AAS $*$ \\
\hline Serum & $253.8 \pm 7.2$ & $244.9 \pm 10.2$ & $248.3 \pm 12.7$ \\
\hline Blood & $302.7 \pm 7.8$ & $290.6 \pm 11.6$ & $295.1 \pm 14.2$ \\
\hline Plasma & $142.5 \pm 3.8$ & $139.4 \pm 5.5$ & $145.6 \pm 6.9$ \\
\hline
\end{tabular}

* Mean of three determinations \pm cconfidence interval $(\mathrm{P}=0.95, \mathrm{n}=5)$,

As low LOD for ET-AAS and ICP-MS the samples diluted with DW before analysis

Table 5. Spiking real samples with a standard solution in human blood, serum and plasma samples by APDC/IL/NGO adsorbent $\left(\mu \mathrm{gL}^{-1}\right)$

\begin{tabular}{llll}
\hline Sample & Added & * Found & Recovery (\%) \\
\hline \multirow{2}{*}{ Serum } & ----- & $123.2 \pm 5.3$ & ---- \\
& 50 & $170.9 \pm 7.6$ & 95.4 \\
& 100 & $225.4 \pm 9.8$ & 102.2 \\
\hline \multirow{3}{*}{ Blood } & ---- & $111.3 \pm 4.9$ & ----- \\
& 50 & $159.4 \pm 6.1$ & 96.2 \\
\hline \multirow{3}{*}{ Plasma } & 100 & $209.8 \pm 9.2$ & 98.5 \\
\hline
\end{tabular}

* Mean of three determinations \pm cconfidence interval $(\mathrm{P}=0.95, \mathrm{n}=5)$ 
Table 6. Comparing of mean lead concentration in human blood of battery workers with control peoples by DIL-SPME procedure $\left(\mu \mathrm{gL}^{-1}\right)$

\begin{tabular}{|c|c|c|c|c|c|c|}
\hline \multirow{2}{*}{ Sample } & \multicolumn{2}{|c|}{ * Mean of Subjects $(n=40)$} & \multicolumn{2}{|c|}{ * Mean of Controls $(n=40)$} & \multicolumn{2}{|c|}{ + Data Subject } \\
\hline & Intra-day & Inter day & Intra-day & Inter day & $\mathrm{r}$ & $P$ value \\
\hline Plasma & $194.2 \pm 8.7$ & $191.5 \pm 8.6$ & $47.1 \pm 2.3$ & $48.4 \pm 2.5$ & 0.090 & $<0.001$ \\
\hline Serum & $401.2 \pm 19.3$ & $397.7 \pm 18.9$ & $94.4 \pm 4.6$ & $90.8 \pm 4.4$ & 0.088 & $<0.001$ \\
\hline Blood & $382.5 \pm 18.4$ & $386.3 \pm 18.6$ & $88.2 \pm 4.1$ & $85.9 \pm 3.9$ & 0.101 & $<0.001$ \\
\hline
\end{tabular}

* Mean of three determinations of samples \pm confidence interval $(\mathrm{P}=0.95, \mathrm{n}=10)$

+ Correlations are based on Pearson coefficients (r). Statistical significance will be observed if $\mathrm{P}<0.001$

Subject and control groups belong to battery workers and control peoples

Table 7. The validation of methodology for lead extraction with certified reference material (CRM, ICP-MS) by DIL-SPME procedure $\left(\mu \mathrm{gL}^{-1}\right)$

\begin{tabular}{lccc}
\hline SRM & Added & Found by $\mu$-SPE ${ }^{+}$ & Recovery (\%) \\
\hline ICP-MS A & ------ & $120.4 \pm 5.7$ & ------- \\
& 50 & $168.1 \pm 7.3$ & 95.4 \\
& 100 & $218.5 \pm 9.9$ & 98.1 \\
\hline ICP-MS B & ------ & $208.7 \pm 9.8$ & ------ \\
& 50 & $260.1 \pm 14.2$ & 102.8 \\
& 100 & $305.4 \pm 14.2$ & 96.7 \\
\hline
\end{tabular}

+ Mean value \pm standard deviation based on three replicate measurements ICP-MS: blood analysis for lead, $\mathrm{A}=122.5 \mathrm{ngL}^{-1}, \mathrm{~B}=210.3\left(\mu \mathrm{gL}^{-1}\right)$

In addition, the blood samples were validated by certified reference materials (CRM, NIST) by DILSPME procedure (Table 7). Based on table 4-7, the precision and accuracy of results was satisfactorily confirmed in human blood samples.

\section{Conclusions}

An applied adsorbent based on APDC/IL/NGO was used for separation, preconcentration and determination of lead in blood samples by the DIL-SPME procedure. The IL was helped to separate the solid phase from liquid matrixes in bottom of conical tube which was modified on NGO. By DIL-SPME procedure, the simple, perfect recovery and fast analysis was achieved for lead at $\mathrm{pH}=6.0$ by APDC/IL/NGO sorbent. The modification of NGO surface with IL/APDChelped to enhance the lead extraction in blood samples. Also, some advantages of proposed method such as, fast separation, low cost, and high extraction caused to comparable to ICP-MS analyzer. The LOD and linear range(LR) has acceptable level for lead analysis in human biological samples. Therefore, the extraction and determination lead with APDC/IL modified on NGO in human blood were simply achieved based on sulfur dative bond in optimized conditions by DIL-SPME procedure before determined by F-AAS. The lead analysis in workplace air was achieved based on NIOSH method for 40 workers and range/mean concentrations in air were obtained 44.7-81.5 $\mu \mathrm{gm}^{-3}$ and $65.6 \mu \mathrm{gm}^{-3}$, respectively for a $200 \mathrm{~L}$ of air sample which was higher than standard of lead in air by NIOSH $\left(50 \mu \mathrm{gm}^{-3}\right)$.

\section{Acknowledgements}

The authors wish to thank from Faculty of Natural resources and Environment, Science and Research branch, Islamic Azad University, Tehran, Iran and Birjand university, Birjand, Iran. 


\section{References}

[1] J. Briffa, E. Sinagra, R, Blundell, Heavy metal pollution in the environment and their toxicological effects on humans, Heliyon, 6 (2020) e04691.

[2] A.L. Wani, A. Ara, J.A. Usmani, Lead toxicity: A review, Int. Toxicol., 8 (2015) 55-64.

[3] Lead toxicity: what Is the biological Fate of Lead in the Body, environmental health and medicine education, Agency for toxic substances and disease registry (ATSDR), 2017. https://www. atsdr.cdc.gov $/ \mathrm{csem} / \mathrm{csem} \cdot \mathrm{asp}$ ?csem $=34 \& \mathrm{po}=9$

[4] M. Tamayo y Ortiz, M.M. Téllez-Rojo, H. Hu, M. Hernandez-Avila, R. Wright, C. Amarasiriwardena, N. Lupoli, A. MercadoGarcia, I. Pantic, H. Lamadrid-Figueroa, Lead in candy consumed and blood lead levels of children living in Mexico City, Environ. Res., 147 (2016) 497-502

[5] J. Wieczorek, A. Baran, K. Urba 'nski, R. Mazurek, A. Klimowicz-Pawlas, Assessment of the pollution and ecological risk of lead and cadmium in soils, Environ. Geochem. Health, 40 (2018) 2325-2342.

[6] J. Ahn, M.Y. Park, M.Y. Kang, I.S. Shin, S. An, H.R. Kim, Occupational lead exposure and brain tumors: systematic review and metaanalysis, Int. J. Environ. Res. Public Health, 17 (2020) 3975.

[7] J.Sirivarasai,S.Kaojarern,S.Chanprasertyothin, P. Panpunuan, K. Petchpoung, A. Tatsaneeyapant, K. Yoovathaworn, T. Sura, S. Kaojarern, P. Sritara, Environmental lead exposure, catalase gene, and markers of antioxidant and oxidative stress relation to hypertension: An analysis based on the EGAT study, Biomed. Res. Int., 2015 (2015) 856319.

[8] F. Aarabi, M. Kusajima, T. Tohge, T. Konishi, T. Gigolashvili, M. Takamune, Y. Sasazaki, M. Watanabe, H. Nakashita, A.R. Fernie, Sulfur deficiency-induced repressor proteins optimize glucosinolate biosynthesis in plants, Sci. Adv., 2 (2016) e1601087.

[9] O. P. Ajsuvakovaa, A. A. Tinkov, Sulfhydryl groups as targets of mercury toxicity, Coord.
Chem. Rev., 15 (2020) 417. http://doi. org/10.1016/j.ccr.2020.213343.

[10] Environmental Protection Agency (EPA), Basic information about lead in drinking water, 2014.

[11] United States Food and Drug Administration (FDA), Elemental impurities guidance for industry, Department of Health and Human Services, p. 41, 2017.

[12] US department of health and human services, national institute for occupational safety and health (NIOSH); Adult blood lead epidemiology and surveillance (ABLES), 2017.

[13] S. Triantafyllidou, J. Burkhardt, Variability and sampling of lead $(\mathrm{Pb})$ in drinking water: Assessing potential human exposure depends on the sampling protocol, Environ. Int., 146 (2021) 106259.

[14] S. Kapitány, D. Nagy, J. Posta, A .Béni, Determination of atmospheric sulphur dioxide and sulphuric acid traces by indirect flame atomic absorption method, Microchem. J., 157 (2020) 104853.

[15] T. Amiri-Yazani, R. Zare-Dorabei, M. Rabbani, A. Mollahosseini, Highly efficient ultrasonicassisted pre-concentration and simultaneous determination of trace amounts of $\mathrm{Pb}$ (II) and $\mathrm{Cd}$ (II) ions using modified magnetic natural clinoptilolite zeolite: Response surface methodology, Microchem. J., 146 (2019) 498508.

[16] P. Montoro-Leal, J.C. García-Mesa, M.T. Siles Cordero, Magnetic dispersive solid phase extraction for simultaneous enrichment of cadmium and lead in environmental water samples, Microchem. J., 155 (2019) 104796.

[17] J.S.F. Pereira, D. P. Moraes, Determination of metals and metalloids in light and heavy crude oil by ICP-MS after digestion by microwaveinduced combustion, Microchem. J., 96 (2010) 4-11.

[18] V. Balaram, Microwave plasma atomic emission spectrometry (MP-AES) and its applications - A critical review, Microchem. J., 159 (2020)105483. 
[19] S.M. S. Khademi, A. Salemi, Development and comparison of direct immersion solid phase micro extraction Arrow-GC-MS for the determination of selected pesticides in water, Microchem. J., 164 (2021) 106006.

[20] V. CâmaraCosta, M. Limade Mello, Calibration strategies for determination of $\mathrm{Pb}$ content in recycled polypropylene from car batteries using laser-induced breakdown spectroscopy (LIBS), Microchem. J., 159 (2020) 105558.

[21] Y. Song, Q. Ma, H. Cheng, J. Liu, Y. Wang, Simultaneous enrichment of inorganic and organic species of lead and mercury in pg L $\mathrm{L}^{-1}$ levels by solid phase extraction online combined with high performance liquid chromatography and inductively coupled plasma mass spectrometry, Anal. Chim. Acta, 1157 ( 2021) 338388.

[22] Y.-K. Li, W. Li, X. Liu, T. Yang, M.L. Chen, J.H. Wang, Functionalized magnetic composites based on the aptamer serve as novel bio-adsorbent for the separation and preconcentration of trace lead, Talanta, 203 (2019) 210-219.

[23] V. de JesusFerreira, J. S.Almeida, Determination of $\mathrm{Cu}, \mathrm{Ni}, \mathrm{Mn}$, and $\mathrm{Pb}$ in diesel oil samples using reversed-phase vortex-assisted liquidliquid microextraction associated with energy dispersive X-ray fluorescence spectrometry, Talanta, 222 (2021) 121514.

[24] A. H. Kame, A.Ei-Galil, E.Amr, Preconcentration based on cloud point extraction for ultra-trace monitoring of lead (II) using flame atomic absorption spectrometry, Appl. Sci., 22 (2019) 4752. https://doi.org/10.3390/ app9224752

[25] M. Ghazaghi, H. Shirkhanloo, H.Z. Mousavi, A.M. Rashidi, Ultrasound-assisted dispersive solid phase extraction of cadmium(II) and lead(II) using a hybrid nanoadsorbent composed of graphene and the zeolite clinoptilolite, Microchim. Acta, 182 (2015)1263-1272.

[26] M. Shokri, A. Beiraghi, S. Seidi, In situ emulsification microextraction using a dicationic ionic liquid followed by magnetic assisted physisorption for determination of lead prior to micro-sampling flame atomic absorption spectrometry, Anal. Chim. Acta, 889 (2015) 123-129.

[27] M. Vesali-Naseh, M. RezaVesali Naseh, P. Amer, Adsorption of $\mathrm{Pb}$ (II) ions from aqueous solutions using carbon nanotubes: A systematic review, J. Clean. Prod., 291 (2021) 125917.

[28] N. Rahman, M. Nasir, P.Varshney, Efficient removal of $\mathrm{Pb}(\mathrm{II})$ from water using silica gel functionalized with thiosalicylic acid: Response surface methodology for optimization, J. King Saud. Un. Sci., 33 (2021) 101232.

[29] N. Manousi, E. Rosenberg, E. A. Deliyanni, Sample preparation using graphene-oxidederived nanomaterials for the extraction of metals, Molecules, 25 ( 2020) 2411. https://doi. org/10.3390/molecules 25102411

[30] S. Mirza, N. Mansouri, R. Arjmandi, R. Azizinejad, Evaluation and comparison of health, safety and environmental management system in oil and petrochemical downstream industries (Case Study of Textile Factories), J. Health safe. Work, 1132-35 (2021) .

[31] W.S.J. Hummers, R.E. Offeman, Preparation of Graphitic Oxide, J. Am. Chem. Soc., 80 (1958) 1339.

[32] M.K. Abbasabadi, A. Rashidi, S. Khodabakhshi, Benzenesulfonic acid-grafted graphene as a new and green nanoadsorbent in hydrogen sulfide removal, J. Nat. Gas Sci. Eng., 28 (2016) 87-94.

[33] M. Khaleghi-Abbasabadi, D. Azarifar, Magnetic Fe3O4-supported sulfonic acid-functionalized graphene oxide (Fe3O4@GO-naphthalene$\mathrm{SO} 3 \mathrm{H})$ : a novel and recyclable nanocatalyst for green one-pot synthesis of 5-oxodihydropyrano[3,2-c]chromenes and 2-amino3-cyano-1,4,5,6-tetrahydropyrano[3,2-c] quinolin-5-ones, Res. Chem. Intermed. 45 (2019) 2095-2118. 